\title{
DOI: $10.37892 / 2218-1393-2020-12-1-149-163$
}

\section{Принцип визуализации в сфере специализированного терминообразования} (на материале русско-английских переводных эквивалентов)

\section{А.К. Зотова (Институт языкознания РАН)}

\begin{abstract}
Аннотация
В статье рассматриваются примеры специальной терминологии ряда естественнонаучных и гуманитарных дисциплин. Основное внимание уделяется моделям, созданным на основе принципа визуализации, их синонимам и русско-английским эквивалентам. Работа основана на современном фактическом материале и может представлять интерес для специалистов в области прикладной лексикографии, а также использоваться в лингводидактических целях.
\end{abstract}

\section{Ключевые слова}

Визуализация, специализированная терминология, терминообразование, языки мира.

Термин визуализация все чаще появляется в научных публикациях в самом разном контекстном окружении. Нас будут интересовать два из них. Первый — это визуализация в значении английского термина imaging. Одним из наиболее характерных научных контекстов, в которых этот термин функционирует, является сфера современных медицинских технологий - medical imaging ‘медицинская визуализация’, в частности magnetic resonance imaging, nuclear medicine functional imaging и др. Не вдаваясь в детали огромного разнообразия и специфики отдельных дисциплин, выделим главное: с помощью этого термина описываются технические приемы, процесс или результат операций и процедур. Это создает удобные для зрительного наблюдения и анализа формы представления происходящего внутри организма человека, например, в процессе эндоскопии. В первую очередь речь идет об использовании рентгенографии, радиографии, инфракрасного, теп- 
лового излучения, ультразвуковых, магнитно-резонансных и целого ряда других медицинских технологий получения изображений для диагностики патологий. В последнее время развивающейся областью неинвазивной противоопухолевой нанотерапии становится тераностика, объединяющая диагностику и терапию с помощью новых фармацевтических препаратов или процедур с целью уменышения травмирующего воздействия на организм больного (от греческого therapeia, прошедшего стадию новолатинского therapia ‘терапия’ и греческого diagnostics 'диагностика'). Одним из наиболее ярких примеров медицинской визуализации является телекоммуникационная медицина, позволяющая проводить диагностические исследования, искать коллегиальные решения и осуществлять сложнейшие хирургические манипуляции дистанционно.

Другим примером функционирования термина визуализащчия является сфера психологии, когнитивных дисциплин, а также естественные, математические и многие другие области знаний. В данном случае речь идет об английском термине visualization. В самой широкой трактовке - это привлечение образности в качестве самостоятельного или дополнительного инструмента при взаимодействии с ментальной или интеллектуальной сферами деятельности человека, например, creative visualization 'созидающая/управляемая визуализация', graphic data visualization 'инфографика', interactive visualization ‘интерактивная визуализация’ и др.

В настоящей статье мы сосредоточимся на анализе одного из типов терминологии - терминов, созданных на основе принципа визуализации. В этом смысле имеет место синтез обеих приведенных выше трактовок термина визуализации. С одной стороны, с помощью терминов этого типа специалисты стремятся представить в наглядной форме исследуемые ими сложные и ненаблюдаемые микро-, нано- и гораздо менее размерные объекты или явления. С другой стороны, им приходится апеллировать к воображению и использовать оптические образы, которые могли бы характеризовать особенности этих объектов и явлений. Одновременно статья продолжает серию исследований особенностей и современных тенденций в области научной и научно-технической терминологии, начатых в предшествующих публикациях автора [3; 4; 5]. 
В настоящей работе мы хотим расширить круг примеров и более внимательно присмотреться к лексическим компонентам и морфолого-синтаксическим типам терминообразовательных моделей. Главным критерием выбора материала является оптическая образность, составляющая основу термина, определяющая его специфику и проблемы, связанные с подбором переводного эквивалента. Особый интерес представляет вопрос о причинах все более активного использования принципа визуализации в специализированной научной лексике и о связях с аналогичными тенденциями в других областях, в частности в медийной и информационной сферах, таких как компьютерная графика или интерактивные телекоммуникация.

В подавляющем большинстве случаев приведенные примеры взяты из современных публикаций на английском языке, в которых описываются исследования, проводимые в крупнейших научных центрах с привлечением специалистов из разных стран. В одном из типичных примеров соавторства можно встретить до 20 имен исследователей из 8-12 университетов США, Китая, Швейцарии, Индии, Японии и других стран.

Тематический диапазон включает в себя исследования в таких областях как химическая медицина, биохимия, молекулярная биология, биофизика, химия полимеров, физика полимеров, квантовая, статистическая физика, термодинамика, теория вероятностей и случайные процессы, топология и др. Иногда тематика бывает настолько узкоспециализированной, что трудно найти текст, который был бы написан носителями эталонного британского стандарта английского языка. В целом, языковой материал этих публикаций представляет собой классический образец international или global English то есть 'международного английского', в котором закрепляются и получают дальнейшее развитие тенденции к унификации и универсализации терминообразовательных моделей. Одной из этих тенденций является использование специальной терминологии, создаваемой на основе принципа визуализации, то есть не путем вербального описания отдельных признаков и свойств, а с помощью графического или образного представления исследуемых объектов с привлечением общеупотребительной лексики. 
В предыдущих публикациях мы уже отмечали частотность использования бытовой лексики в составе многокомпонентных терминологических сочетаний в английском языке: jacketed reactor т.е. 'реактор с рубашкой' в сфере промышленных химических технологий, riding atom, переводимый на русский язык как 'атом-наездник', apronectomy — ‘апронэктомия’ (от английского apron - ‘фартук’ и ectomy - ‘удаление', восходящего к греческому этнониму) и его профессиональный синоним 'удаление фартука' в пластической хирургии $[4,141-142]$. Но в данном случае нас интересует не сам по себе факт использования общеязыковой или бытовой лексики, а содержание и характер создаваемых с ее помощью образов, то есть собственно изобразительный потенциал этих терминов. Описываемые ими объекты сложны, многоаспектны и многомерны, поэтому их визуальное представление выходит за рамки возможностей обычной, например, акустической метафоры типа шипящая $=$ первая или свистящая $=$ вторая аккомодаџия с их более сдержанными устойчивыми английскими эквивалентами ‘Slavic I Palatalization' и ‘Slavic II Palatalization' в палеославистике [10, 109]. Простота и степень наглядности терминов, создаваемых на основе принципа визуализации, делает их емкими, однозначно понимаемым и универсальными.

Из ряда характерных терминологических словосочетаний с использованием бытовой лексики - DNA hairpin 'шпилька ДНК', Mexican hat 'мексиканская шляпа', braid group 'группа кос', bottle-brush polymer 'полимерная щетка' bamboo-type nanotube 'нанотрубка бамбукового типа', China-lantern complex или его денотатный синоним paddlewheel 'комплекс в виде китайского фонарика/гребного колеса' и т.п. - выберем термин two-legged piano-stool geometry ‘геометрия «стул для пианино»'. С точки зрения структуры мы имеем дело с терминологическим словосочетанием, состоящим из трех компонентов - сложного прилагательного и двух существительных, первое из которых в свою очередь двусоставно. Функционально компоненты этого словосочетания образуют атрибутивный комплекс, который называется noun chain — 'определительная цепочка существительных' или 'определительный ряд существительных' и в котором каждый член характеризует признак соседнего, в данном случае последующего, компонента. Особый ин- 
терес представляет лексический состав и потенциальные средства его передачи с помощью русского эквивалента. Существительное geometry 'геометрия' представляет собой термин с вполне устоявшимся набором значений, основным из которых является общенаучный термин - название науки. Высокочастотным можно считать использование этого термина в составе словосочетаний, построенных на основе метонимии, с переносом значения родового понятия на видовое. В таких случаях при переводе можно конкретизировать значение термина с помощью выбора соответствующего эквивалента из иерархического ряда по шкале общее - частное, что в принципе вполне типично для практики перевода с английского языка на русский. Следует отметить, однако, что в последнее время такие замены происходят все реже и реже, и в научных текстах закрепляется тенденция передачи общенаучных терминов с сохранением соответствующих однотипно структурированных метонимических моделей. В большинстве случаев специалисты скорее всего сохранят более общий термин, и в качестве его русского эквивалента будет фигурировать слово геометрия, а не структура, например. Вернемся к атрибутивной части этого сложного термина - a two-legged piano-stool 'стул для пианино'. В данном случае перевод не вполне корректен, поскольку английское существительное stool означает 'табурет(ка)', ‘скамья’ или ‘подставка', ‘столбик' 'опора' [B; LS; LU], а не только ‘стул’, что в данном случае имеет принципиальное значение для адекватной передачи создаваемого зрительного образа. Кроме того, исходный термин сокращен за счет удаления громоздкого прилагательного. Такая вынужденная мера упрощения бывает необходима и часто используется при переводе многокомпонентных терминов. Например, конструкция twistedboat molecule conformation приобретает вид twist-boat conformation, а затем еще более компактный вариант twist-boat, которому в русскоязычной литературе соответствуют термины 'изогнутая лодка' или 'твист-форма'. Если первый из них - просто калька, то во втором мы имеем образец сразу нескольких преобразований при переводе: 1) транслитерация twist $\rightarrow$ твист, 2) метонимическое расширение лодка $\rightarrow$ форма', которое сопровождается заменой бытовой лексики на общенаучную, и 3) агглютинативное соединение основ, написанное через дефис. 
Во многих других случаях термины, включающие в себя метафоризированные элементы на базе английской общеупотребительной лексики, не имеют лаконичных терминологических соответствий в русском языке и могут быть переведены только с помощью интерпретирующих описательных эквивалентов, например, nutshell graph — 'ненаправленный/неориентированный (квантовый) граф’ или неорграф в профессиональном подъязыке (теория графов). Принятый в настоящее время в химии термин one-pot protocol может выглядеть как ‘однореакторный синтез’ или ‘метод синтеза без выделения промежуточных продуктов’, click-chemistry 'клик-химия' - концепция надёжных и простых модульных химических реакций.

Во избежание перегруженности текста, создаваемой такими конструкциями, специалисты стремятся упростить и унифицировать научную терминологию, в частности, с помощью синтаксического калькирования иноязычных, преимущественно английских и немецких, конструкций. При переводе английской атрибутивной структуры прилагательное + существительное предпочтение отдается однотипной синтаксической структурной модели, которая начинает преобладать над парой существительное + существительное в родительном падеже, например: reactional conditions в значении 'условия реакции' в химии или nominal and verbal morphology в значении ‘морфология имени и глагола' в языкознании $[4,189 ; 5,142]$. Еще один пример структурной кальки можно привести из области медицины - термин coronavirus 'коронавирус' и возникающие на его основе и сходные с ним по форме квазитермины типа coronacrisis 'коронакризис' и др. Первое, что бросается в глаза, это словоообразовательная модель, основанная на принципе морфолого-синтаксического калькирования, а именно сложения основ по агглютинативному типу вопреки правилам словосложения в русском языке с помощью соединительных гласных, в данном случае гласной -о-. Примеры такого типа множатся постоянно, не только в сфере фармацевтики, например в названиях лекарственных препаратов типа Фибрапласт, но и в специальной терминологии экономических, социетальных исследований и естественнонаучных дисциплин. 
Унификация может осуществляться путем замены отдельных аффиксальных элементов на более общие и универсальные. Так в составе сложного английского термина на основе современной общенаучной лексики non-network polymer 'неразветвленный полимер’ функцию отрицания берет на себя префиксальная частица поn- при наличии устоявшихся синонимов прилагательного unbranched или unramified 'неразветвленный', закрепленных в специальных словарях [LU; LS; BD].

При подборе русского переводного эквивалента наблюдаются ослабление доминанты терминообразовательных моделей на базе греко-латинских элементов, более частые замены переводов специальных научных терминов на калькированные, образные многокомпонентные и разнородные по морфологической структуре эквиваленты.

В случае терминологических лакун, то есть при отсутствии терминов, морфологически и структурно близких и регулярно употребляющихся в профессиональном узусе, поиски продолжаются вплоть до полного отказа от русскоязычного эквивалента, например как в случае словосочетаний с участием компонента push-pull ‘двухтактный’ [LHD; LU]. Только в английском толковании этого словосочетания говорится о том, что это: 1) прилагательное, 2) относящееся к электронике и 3) описывающее что-либо не только как двухфазное, но разнонаправленное, т.е. 'противофазное' (adjective, Electronics, operated by pushing and pulling — having or involving two matched valves or transistors that operate 180 degrees out of phase...) [OD]. К сожалению, ни один из двуязычных англо-русских словарей не содержит близкого варианта, что ставит этот случай в ряд других безэквивалентных терминоэлементов, при переводе которых каждый раз необходим специальный контекстный перевод. В нашем случае словосочетанию push-pull nature соответствует русский аналог 'противофазная природа', но в других текстах можно обнаружить ‘пушпульный' или воспроизведенный в оригинальном виде push-pull в препозиции к определяемому существительному. Если первый из этих вариантов представляет собой образец “профессионального просторечия” $[11,71]$, то второй иллюстрирует новый тип комбинированной двуязычной терминообразовательной модели в русском языке. 
Еще одна универсальная модель, которая все чаще проникает в научный обиход из сферы рекламы и массовой коммуникации и используется в технической или естественнонаучной сфере, это так называемые термины-цифрограммы и типограммы, включающие в свой состав числовые или буквенные символы в качестве самостоятельной или дополнительной атрибутики на основании сходства графических, зрительных или акустических характеристик [5,142-143].

В ряде случаев, однако, при переводе встречаются стилистические расхождения, которые влекут за собой изменения не только на уровне морфологии отдельных терминологических моделей, но и в научном тексте в целом. В одной из программ по изучению социально-экономических проблем народонаселения обнаруживаются предложения типа We need ... to revise this roadmap in the light of EU-Russia S\&T cooperation. При передаче английской аббревиатуры $S \& T=$ scientific and technological в научном тексте на русском языке используется преимущественно полная форма словосочетания 'научнотехнический’. Цепное нанизывание разнотипных аббревиатур создает ощущение совершенно нехарактерной для русского языка стилистики нерегламентированного научного текста. В последнее время скопление акронимов и сокращений становится типичным для устной и письменной речи в средствах массовой информации, в титрах новостных телевизионных программ и электронных публикациях. В этом смысле английский пример интересен еще и тем, что в нем присутствует знак конъюнкции - символ амперсанд, который характерен в первую очередь для рекламы, названий брендов или медийной графической стилистики.

Интересно отметить специфику терминообразовательных моделей в британском (BE), американском (AE) и международном (International/World/Global English) вариантах английского языка. С одной стороны, типичным для всех трех является наличие большого разнообразия синонимов типа disposable = one-off = single-use в значении 'одноразовый' или superluminal, superlumic, hyperlight, hyperlightspeed или его американский и международный аналог faster-than-light в значении 'сверхсветовой', которому в русском языке также соответствует интерпретирующий перевод 'превышающий скорость распро- 
странения света'. При этом последние адъективированные термины (single-use и fasterthan-light соответственно) можно отнести к числу созданных на основе упрощенной унифицированной модели, которая делает их менее терминологизированными с точки зрения лексического состава и структуры, но более терминологичными, то есть однозначными, непротиворечивыми и универсальными по содержанию. На практике возможно и часто наблюдается параллельное и одновременное (симметричное, а иногда и асимметричное) использование терминов-синонимов, относящихся к разным типам. Одним из последних бросающихся в глаза примеров синонимов такого рода можно считать параллельное функционирование терминов confinement в значении 'ограничение' [LU], quarantine/quarantining, lockdown 'изоляция (инфекционного больного)' isolation и их русских эквивалентов 'карантин/карантинизация/карантинная изоляция'. Стремительное развитие пандемии COVID-19 и нарастающая лавина связанных с ней публикаций дают возможность отчетливо проследить динамику в использовании этих терминов в связи с их принадлежностью к вариантам английского языка. Самым привычным и устоявшимся из этого ряда является quarantine 'карантин', который появился в середине XVII в. и по горькой иронии восходит к итальянскому quarantina ‘сорок дней’ [CC]. Он легко конвертируется в глагол и включается в словоизменение quarantined, quarantining. В средствах массовой информации менее употребительное существительное confinement 'ограничение (в передвижении)' и даже ‘заключение под стражу’ довольно быстро было замещено более прозрачным американским lockdown 'локдаун; строгая изоляция в целях безопасности' [OD]. По мере расширения географии инфекции и необходимости разъяснения ситуации, соблюдения профилактики и призывов к методам борьбы с пандемией в документах ВО3 [12] сразу же появился и закрепился самый доступный для понимания и универсальный по внешней и внутренней структуре self-isolation, производный от в равной степени общенаучного и бытового isolate ‘выделять; изолировать; разобщать' [CC; LS; LU] со всем спектром возможностей его формоизменения и словообразования [13].

Хотелось бы привести особый случай неупотребления специальной терминологии и замены ее невербальными средствами представления данных в тексте научного описа- 
ния. Этот неожиданный пример был обнаружен нами в ходе создания лингвистического контента обновленной версии базы данных «Языки мира» Института языкознания РАН, a именно при анализе описаний фонетического состава языков в статьях энциклопедии «Языки мира».

В ряде статей, посвященных описанию германских, кельтских и иранских языков, используются особые схемы, которые отражают попытки авторов в той или иной степени адекватно представить качественный диапазон гласных фонем. Эти схемы имеют вид симметричных или асимметричных геометрических форм различной конфигурации с разным количеством вершин, пунктирных линий и стрелок. В текстах статей они могут использоваться самостоятельно и не сопровождаться терминологической интерпретацией качественных признаков фонем - ряд, подъем, огубленность и др. В комментарии (если он есть) может содержаться информация о количественных признаках гласных - оппозиции по долготе/краткости, наличии сверхкратких или редуцированных звуков и др.

Потребность в визуализации данных с помощью графики в тексте лингвистического описания обусловлена несколькими причинами. В первую очередь, системы вокализма в этих языках крайне сложны, динамичны не только в диахронном, но и синхронном состоянии $[9,15]$. Например, особенностью вокализма иранских языков является система качественно-количественных оппозиций, не только бинарных, но и трихотомических. Сложность этой системы частично описывается с помощью терминов, но в большинстве статей авторы используют графические схемы, что отличает их тексты от традиционных описаний языков других семей - славянских или романских. Например, в статье «Талышский язык» $[2,91]$ :

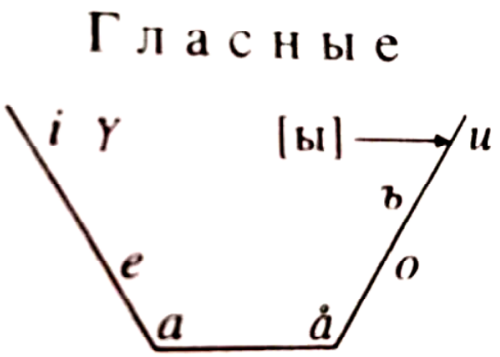


В статье «Белуджский язык» стрелками и пунктирными линиями показан качественный диапазон кратких гласных. Речь идет о том, что противопоставление по признаку долгота/краткость коррелирует с противопоставлением по признаку устойчивость/неустойчивость $[8,32]$ :

\section{Гл а с ны е}

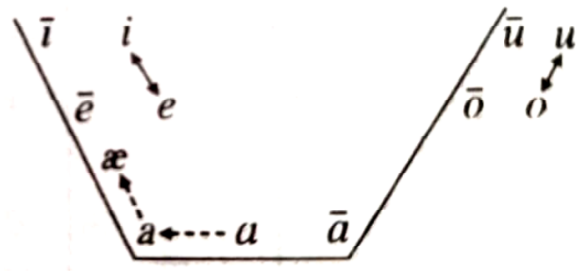

Во-вторых, могут иметь место несколько вариантов, как территориальных диалектов, так и социолектов, собственно дифтонгов и дифтонгоидов и др. Например, в норвежском языке [1, 305]:

Гл а с н ы е

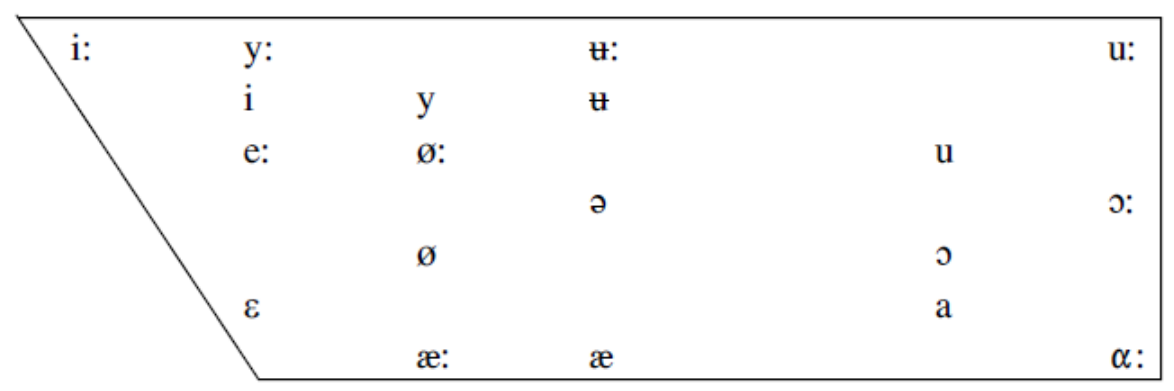

При отсутствии однозначной трактовки специалистами могут приводиться несколько изображений, например в случае с датским языком [7, 131-132]:

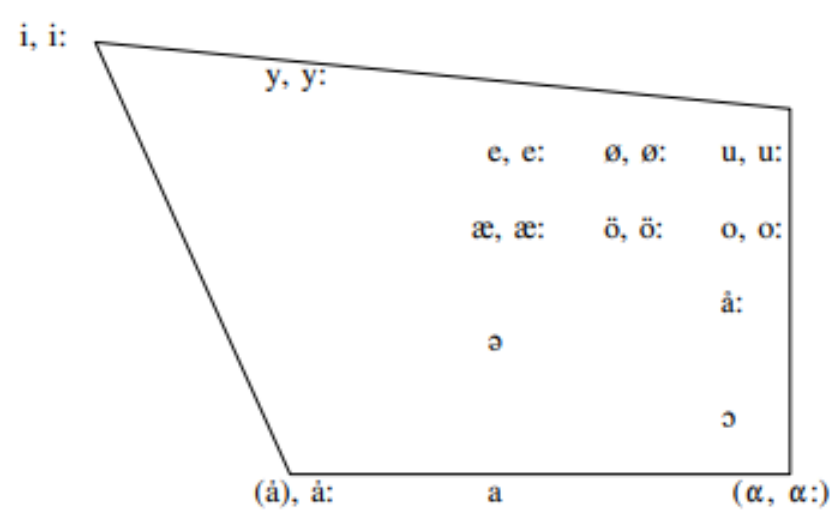

или 


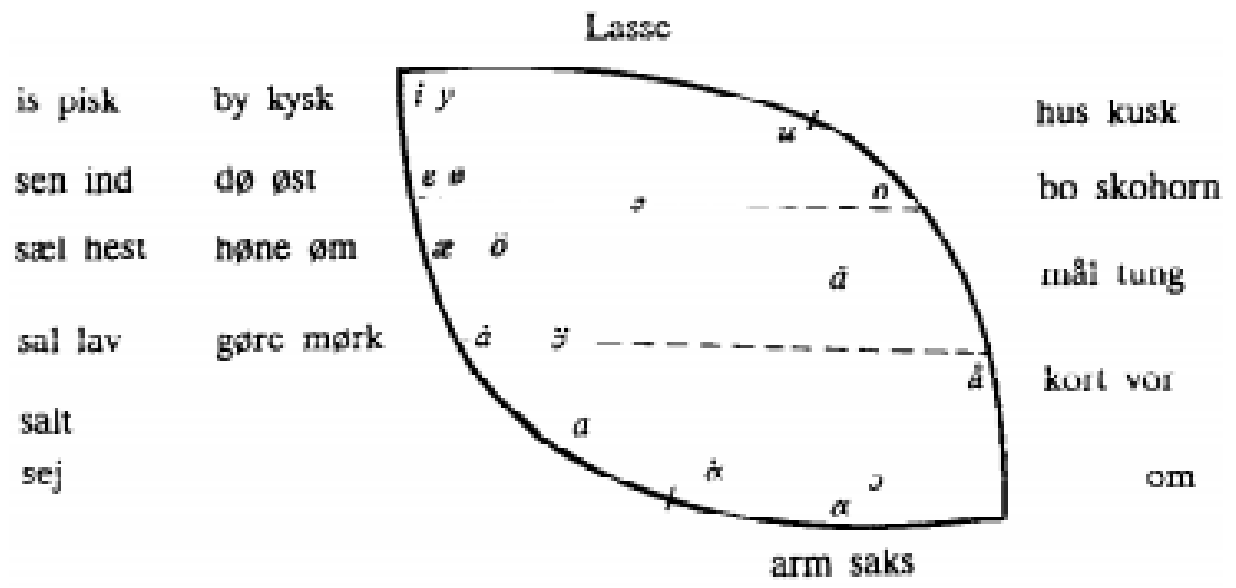

Поиски оптимальной формы представления данных о вокализме языка при сложности системы и различиях в традициях можно проиллюстрировать на примере особой графической схемы гласных и дифтонгов в статье об ирландском языке $[6,430]$ :

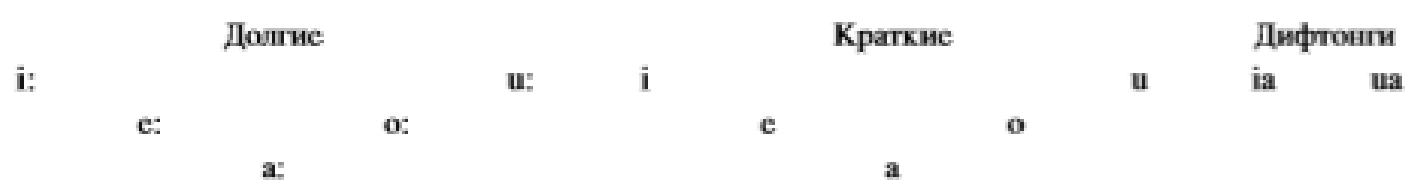

Подводя итоги можно сказать, что природа принципа визуализации в области специального терминообразования, как минимум, двояка. С одной стороны, этот принцип отражает потребность выхода за пределы непространственного (линейного или двухмерного) представления знаний, замены характеризации (транслитерированный английский термин characterization, получивший широкое распространение в сфере естественнонаучных дисциплин) статических свойств на описание многомерных объектов и сложных динамических процессов (биоинженерия, химическая медицина и др.). В этом случае принцип визуализации представляет собой поиск средств представления понятий высокого уровня абстракции, нематериальных, невидимых и ненаблюдаемых макро-, микроили еще менее размерных структур и понятий (гуманитарные науки, теория информации, математическое моделирование и др.). К данному типу объектов можно отнести и приведенные выше примеры лингвистических описаний, а также иллюстраций при реконструкции вымерших или бесписьменных языков с помощью глоттохронологии, палеолингвистики и других методов сравнительно-исторического языкознания на основании 
ограниченного числа эпиграфических источников или когда точная фонетическая транскрипция затруднена графикой (руническое, консонантное письмо, иероглифика и др.).

В то же время многообразие и стремительная динамика роста числа терминовнеологизмов на основе однозначно понимаемых зрительных образов отражает стремление упростить средства терминообразования, найти универсальные терминообразовательные модели в условиях взаимопроникновения областей знания, сближения науки и технологий, развития междисциплинарных исследований и интернационализации научного обмена.

\section{Список сокращений}

B — Building (En-Ru) (к версии ABBYY Lingvo х6). Быков B.В., Поздняков А.А. Англо-русский словарь по строительству и новым строительным технологиям. 65 тыс. слов и словосочетаний. М.: Русский язык-Медиа, 2003//ABBYY $\backslash$ Lingvo $\backslash 16.0$ $\backslash$ Dic $\backslash$ System $\backslash$ BuildingEnRu.lsd.

BD - Biology (En-Ru) (к версии ABBYY Lingvo х6). Чибисова О.И., Смирнов Н.Н. и др. Новый англо-русский биологический словарь. 72 тыс. статей. М.: РУССО, 2003 // ABBYY\Lingvo \16.0 \Dic \System \BiologyEnRu.lsd.

CC - Collins Cobuild (En-En) (к версии ABBYY Lingvo x6). Collins Cobuild. Advanced Learner's English Dictionary. New Digital Edition. HarperCollins Publishers, 2008 // ABBYY \Lingvo $\backslash 16.0 \backslash$ Dic $\backslash$ System $\backslash$ CollinsCobuildEnEn.lsd.

CED — Collins English Dictionary // http://www. collinsdictionary.com.

LHD - Abbyy Lingvo Hover Dictionary (En-Ru) (к версии ABBYY Lingvo х6) // ABBYY $\backslash$ Lingvo $\backslash 16.0 \backslash$ Dic $\backslash$ System $\backslash$ HoverDictionaryEnRu.1sd.

LS — LingvoScience (En-Ru) (к версии ABBYY Lingvo х6) Англо-русский научнотехнический словарь (The English-Russian Scientific Dictionary): около 140 тыс. статей. - 7е изд., испр. и доп. АBВYY //ABBYY \Lingvo $\backslash 16.0 \backslash$ Dic $\backslash$ System $\backslash$ LingvoScienceEnRu.lsd.

LU — LingvoUniversal (En-Ru) (к версии ABBYY Lingvo х6) Англо-русский словарь общей лексики. 100 тыс. статей. ABBYY, 2014. // ABBYY \Lingvo $\backslash 16.0 \backslash$ Dic $\backslash$ System $\backslash$ LingvoUniversalEnRu.lsd 
MD — Medical (En-Ru) (к версии ABBYY Lingvo х6) Ривкин В.Л. Новый англорусский медицинский словарь. 75 тыс. слов и словосочетаний. М.: Руссо, 2004 //ABBYY\Lingvo $\backslash 16.0 \backslash$ Dic $\backslash$ System $\backslash$ MedicalEnRu.lsd.

OD — Oxford Dictionary (En-En) (для ABBYY Lingvo х6) Oxford Dictionary of English. Oxford University Press, 2010 // ABBYY \Lingvo $\backslash 16.0 \backslash$ Dic \System\OxfordDictionaryEnEn.1sd.

\section{Литература}

1. Берков В.П. Норвежский язык // Языки мира. Германские языки. Кельтские языки. М.: ACADEMIA, 2000.

2. Виноградова С.П. Талышский язык // Языки мира. Иранские языки. Иранские языки. II Северо-западные иранские языки. М.: Индрик, 1999.

3. Зотова А.К. Специализированные электронные ресурсы: терминосистема базы данных «Языки мира» и проблемы разработки русско-английского синонимического терминологического указателя // Лингвистика и методика преподавания иностранных языков. Периодический сборник научных статей. Электронное научное издание. М.: ИЯз РАН, 2017. Выпуск № 9. С. 180-191 // http://www.iling-ran.ru/library/sborniki /for_lang/2017_09/7.pdf.

4. Зотова А.К. Некоторые особенности современной лингвистической терминологии (на материале базы данных «Языки мира» Института языкознания РАН) // Лингвистика и методика преподавания иностранных языков. Периодический сборник научных статей Электронное научное издание. М.: ИЯз РАН, 2018. Выпуск № 10. С. 128-139// https://iling-ran.ru/library/sborniki/for_lang/2018_10/7.pdf.

5. Зотова А.К. Терминосистема базы данных «Языки мира»: полисемия и синонимия сквозь призму перевода (на материале проекта синонимического терминологического русско-английского указателя к базе данных «Языки мира» ИЯз РАН) // Лингвистика и методика преподавания иностранных языков. Периодический сборник научных статей. Электронное научное издание. М.: ИЯз РАН, 2019. Выпуск № 11. С. 133-145 // https://iling-ran.ru/library/sborniki/for_lang/2019_11/7.pdf. 
6. Королев А.А., Калыгин В.П. Ирландский язык // Языки мира. Германские языки. Кельтские языки, М.: Academia, 2000.

7. Кузнецов С.Н., Никуличева Д.Б. Датский язык // Языки мира. Германские языки. Кельтские языки. М.: Academia, 2000.

8. Мошкало В.В. Белуджский язык // Языки мира. Иранские языки. II Северозападные иранские языки. М.: Индрик, 1999.

9. Расторгуева В.С. Иранские языки // Языки мира. Иранские языки. I Югозападные иранские языки. М.: Индрик, 1997.

10. Реформатский А. А. Введение в языковедение // http://www.bsu.ru/content/ page/1415/hecadem/reformatsky_aa/reformatsky.pdf.

11. Суперанская А.В., Подольская Н.В., Васильева Н.В. Общая терминология: Вопросы теории. Изд. 5-е. М.: Книжный дом ЛИБРОКОМ, 2009.

12. BBC // https://www.bbc.com/news/uk-51506729.

13. BBC - "Coronavirus: What are social distancing and self-isolation?" https://www.bbc.com/news/health-51048366.

\section{Visualisation principle in specialised terminology: English-Russian translation patterns}

\section{A.K. Zotova (Institute of Linguistics,} Russian Academy of Sciences)

The paper outlines the ways of specialised terminology formation based on visualisation principle. Special attention is paid to the English and Russian terminological pattern specifics. The analysis is supported by up-to-date scientific disciplines' terminology and could be of interest for those dealing with applied lexicography and foreign language pedagogy.

Keywords: Visualization, specialised terminology, terminological patterns, world languages. 